\title{
Porous Ceramic Bodies with Interconnected Pore Channels by a Novel Freeze Casting Technique
}

\author{
Kiyoshi Araki* and John W. Halloran ${ }^{\star, \star *, \dagger}$ \\ Department of Materials Science and Engineering, University of Michigan, Ann Arbor, Michigan 48109
}

\begin{abstract}
Porous ceramic bodies with interconnected pore channels were fabricated by a novel freeze casting technique using camphenebased slurries. The pore channels are surrounded by almost fully dense walls and have nearly circular cross-sections. The pore volume fraction and the channel size were controllable by the solid content in the slurry. The channels are replicas of entangled dendrites of frozen camphene, which sublimed during the freeze-drying process. This porous structure with entangled pore channels is considered potentially useful in many applications such as implantable bone scaffolds.
\end{abstract}

\section{Introduction}

$\mathrm{P}$ OROus bulk ceramics are widely used for industrial applications such as liquid or gas filters, catalysis supports, gas distributors, preforms for metal-impregnated ceramic-metal composites, and implantable bone scaffolds. Porous ceramics can be classified into seven general categories ${ }^{1}$ in terms of pore geometry: (1) foam, (2) interconnected, (3-5) pore spaces between particles, plates, and fibers, respectively, and $(6,7)$ largesmall pore networks (i) and (ii). Among these categories, porous ceramics with interconnected pore channels, preferably aligned channels, are recently attracting much attention because they are expected to have both higher fluid permeability and higher mechanical strength. ${ }^{1}$ Even superior osteoconductivity and higher mechanical strength would be expected for calcium phosphates due to a high degree of uniform pore size and interconnection. ${ }^{2}$

To fabricate ceramic bodies with pore channels, there are two successful techniques: (a) phase separation followed by leaching and (b) freeze casting followed by freeze-drying. Phase separation is usually conducted by spinodal decomposition ${ }^{3-5}$ to yield continuous phases, one of which is later leached to create channels. For example, bulk glasses with interconnected pores or channels have been fabricated by heat treatment for spinodal decomposition, followed by acid leaching of one phase. ${ }^{6,7} \mathrm{Be}-$ cause such glasses usually have a channel size smaller than $0.1 \mu \mathrm{m}$, the permeability of fluid is low. Furthermore, the glasses themselves have poor mechanical properties and poor thermal and chemical stability. Another example of the phase separation technique is the simultaneous occurrence of spinodal decomposition and sol-gel transition in an aqueous solution containing both silicon-based alkoxide and organic polymers. ${ }^{8-11}$ With this technique, channels of $0.2-30-\mu \mathrm{m}$ diameter can be obtained ${ }^{10}$ after washing out the polymer-rich liquid phase. Mesopores can be created in the gelled body. ${ }^{11}$ However, only a limited range of materials, mainly $\mathrm{SiO}_{2}$-based, are applicable to this technique. Another recent unique example of the phase separation technique, which is not induced by spinodal decomposition, is the mechanical mixing of two immiscible fluids, such as hydroxy-

C-H. Hsueh - contributing editor

\footnotetext{
Manuscript No. 10524. Received September 10, 2003; approved September 23, 2004 ${ }^{*}$ Member, American Ceramic Society.

"Fellow, American Ceramic Society.

Author to whom correspondence should be addressed. e-mail: peterjon $@$ umich.edu
}

apatite aqueous slurry and gelcastable methylmethacrylate (MMA) monomer. ${ }^{12}$ Although fully connected channels are obtained by this technique, the channel sizes are relatively large and widely distributed from 100 to $1000 \mu \mathrm{m}$.

For freeze casting techniques, slurries with lower solids contents are first frozen to obtain vehicle crystals, usually ice, and often connected with each other in dendritic shapes, surrounded by frozen concentrated slurry. The frozen body is then freezedried to create channels, which replicate shapes of the connected frozen crystals, and sintered. Yokota ${ }^{13}$ fabricated $\mathrm{MgO}$ and $\mathrm{Al}_{2} \mathrm{O}_{3}$ sintered bodies with aligned interconnected pores by unidirectional freeze casting of magnesium or aluminum sulfate aqueous solution, followed by freeze-drying and sintering. However, the porosity was as high as $90 \%$ in this method and the mechanical properties were poor. Sintered bodies of $\mathrm{Al}_{2} \mathrm{O}_{3}$ and $\mathrm{Si}_{3} \mathrm{~N}_{4}$ with aligned channels have been fabricated by unidirectional freeze casting of conventional aqueous ceramic slurries ${ }^{14-16}$ or silica-sol containing ceramic slurries. ${ }^{17}$ Although all sintered bodies have channels with the connected dendritic shapes of ice crystals, the cross-section of the dendritic channel is a flat ellipsoid with a longitudinal axis of about $500 \mu \mathrm{m}$ and a transverse axis of around $30 \mu \mathrm{m}$. This flat ellipsoidal shape comes from the sheet-like shape of the ice dendrite. ${ }^{18}$

Freeze casting ${ }^{19-22}$ is a forming technique where ceramic slurry, which is usually aqueous and sometimes containing silica-sol, is frozen in a mold at an extremely cold temperature, e.g., $-40^{\circ} \mathrm{C}$, followed by demolding and vehicle removal by sublimation, i.e., freeze-drying, to obtain a green body. Dense sintered bodies are often fabricated by this technique. ${ }^{20,22}$ To eliminate the expensive freezing process under the extremely cold temperature and troublesome freeze-drying process at under $0^{\circ} \mathrm{C}$, the authors recently developed a new freeze casting technique capable of manufacturing near room temperature using camphene, $\mathrm{C}_{10} \mathrm{H}_{16}$, as a vehicle, and showed that a dense $\mathrm{Al}_{2} \mathrm{O}_{3}$ sintered body was obtained. ${ }^{23}$ Camphene is a natural, nontoxic material, so the new technique is even environmentally friendly, unlike other room-temperature freeze casting techniques ${ }^{24,25}$ with nonenvironmentally friendly material as a vehicle.

In this paper, we present porous ceramic bodies with unique channels having nearly circular cross-sections, which are fabricated by our novel freeze casting technique using camphenebased slurries with lower solid contents. The features and the formation mechanism of the porous structures are also reported and discussed.

\section{Experimental Procedure}

\section{(1) Materials}

Alumina was chosen as a model ceramic, using a common $\alpha-\mathrm{Al}_{2} \mathrm{O}_{3}$ powder (AG16, Alcoa Chemical, Pittsburgh, PA) with a median size $\left(d_{50}\right)$ of $0.4 \mu \mathrm{m}$, specific surface area of $8.6 \mathrm{~m}^{2} / \mathrm{g}$, and density of $3.91 \mathrm{~g} / \mathrm{cm}^{3}$ (all from the manufacturer's specifications). For a sublimable vehicle, we used $( \pm)$-camphene $\left(\mathrm{C}_{10} \mathrm{H}_{16}\right.$, CAS79-92-5, Alfa Aesar/Avocado Organics, Ward Hill, MA) with a melting temperature of $44^{\circ}-48^{\circ} \mathrm{C}$ (from the manufacturer's specifications) and a measured liquid density of $0.833 \mathrm{~g} / \mathrm{cm}^{3}$ at $55^{\circ} \mathrm{C}$, without further purification. To produce 
stable $\mathrm{Al}_{2} \mathrm{O}_{3}$ suspensions in liquid camphene, we used for the dispersant an amine derivative of a fatty acid condensation polymer (Perfad 9100, UniQema, Everburg, Belgium). Perfad 9100 is a liquid product with a measured density of $0.963 \mathrm{~g} / \mathrm{cm}^{3}$ at $55^{\circ} \mathrm{C}$ and viscosity of 1.4-2.4 Pa.s (from the manufacturer's specifications).

\section{(2) Fabrication Procedures}

The fabrication procedure is outlined in Fig. 1. Suspensions were prepared by ball-milling the powder in warm liquid camphene (warm ball-milling). Appropriate amounts of $\mathrm{Al}_{2} \mathrm{O}_{3}$ powder, dispersant, and solid camphene were put into sealed high-density polyethylene bottles with pre-warmed $\mathrm{Al}_{2} \mathrm{O}_{3}$ milling media. They were ball-milled inside an oven at a temperature of $55^{\circ} \mathrm{C}$ for $20 \mathrm{~h}$ to produce stable, dispersed slurries. Slurries with initial solid contents of $20,30,40$, and $49.5 \mathrm{vol} \%$ were prepared in $10-20 \mathrm{~cm}^{3}$ batches. The dispersant concentration was always with $2 \mathrm{wt} \%$ dispersant (to $100 \mathrm{wt} \% \mathrm{Al}_{2} \mathrm{O}_{3}$ powder).

The liquid camphene at $55^{\circ} \mathrm{C}$ has a vapor pressure of 2.0 $\mathrm{kPa},{ }^{26}$ which is similar to water at $18^{\circ} \mathrm{C}$, but evaporates faster than water. No camphene was lost by evaporation during warm ball-milling, since the bottle was sealed. However, several percent of camphene was lost during handling, so the actual volume fraction of camphene during casting was determined by measurements on cast samples. The actual solid content in the slurry was calculated with the weight change after complete sublimation of camphene from the cast bodies made by the slurry on the assumption that the weight change corresponds to the camphene weight in the slurry after warm ball-milling. Hereafter, the term "solid content" means this actual solid content.

The warm slurries were then poured into polyurethane molds at room temperature to produce a disc $10 \mathrm{~mm}$ in diameter and $5 \mathrm{~mm}$ thick. After casting, the slurries quickly started to solidify and, typically within $3 \mathrm{~min}$, the solidification was complete to yield a solid green body.

After demolding, green bodies were placed in an ambient atmosphere with an airflow rate of $0.01-0.05 \mathrm{~m} / \mathrm{s}$ to sublime the frozen camphene from the green bodies. Judging from the weight change, the sublimation process typically finished in $24 \mathrm{~h}$. During this freeze-drying process, negligible shrinkage was observed. After the freeze-drying process, the cast bodies were sintered at $1600^{\circ} \mathrm{C}$ (ramping rate of $5^{\circ} \mathrm{C} / \mathrm{min}$ ) for $4 \mathrm{~h}$ without any special binder burnout process.

\section{(3) Characterization}

The bulk density, open porosity, and closed porosity of sintered bodies were measured using the water displacement method ${ }^{27}$ based on the Archimedes principle. Microstructure of the sin-

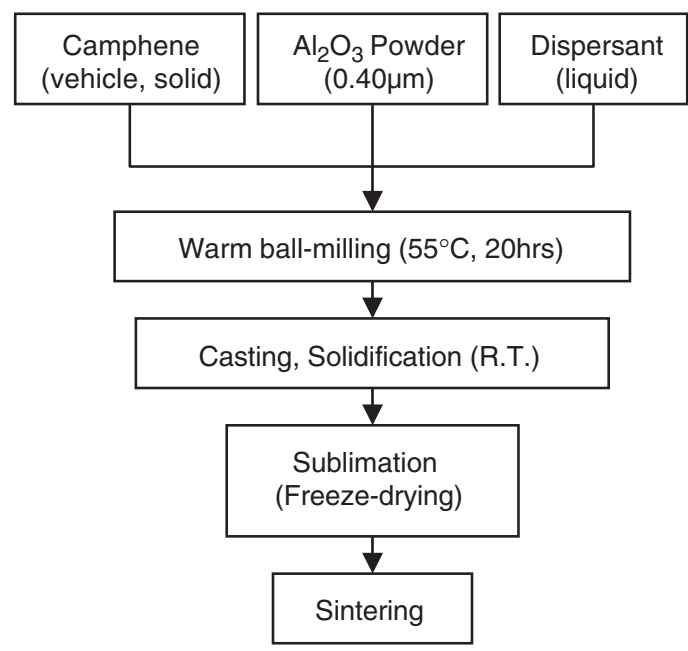

Fig. 1. Schematic chart of the fabrication procedure.

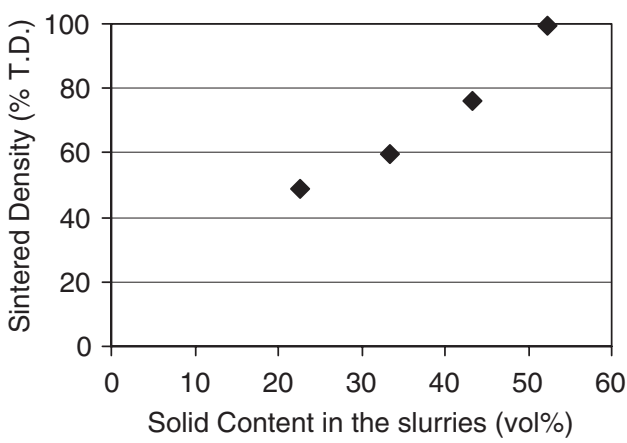

Fig. 2. Relationship between the relative density of sintered bodies and the solid content in the slurries.

tered bodies was observed with scanning electron microscopy (SEM; XL-30, Philips Electronics N.V., Eindehoven, the Netherlands). Solidification behavior of the dilute (3 vol\%) camphene-based slurry was observed with optical microscopy (OM; BH2-UMA, Olympus, Tokyo, Japan) in a transmission mode.

\section{Results}

\section{(1) Microstructure of Cast Bodies}

Previous work ${ }^{23}$ showed that a dense $\mathrm{Al}_{2} \mathrm{O}_{3}$ sintered body was obtained when the camphene-based slurry with a solid content of $50.8 \mathrm{vol} \%$ was used. Figure 2 shows the relative density of the sintered bodies as a function of the solid content in the slurry. The sintered density decreases with decreases in solids contents in the slurry, as expected, and reaches around 50\% theoretical density (TD) when the solids contents in the slurry are decreased to $22.6 \mathrm{vol} \%$.

The microstructures of these sintered bodies are summarized in Figs. 3 and 4. Although the sintered body from the 52.3 vol\% solids content slurry is dense, except for small closed pores (Figs. 3(a) and 4(a)), interconnected pore channels are observed in samples from lower solids content slurries. The channeled structure exists throughout the sintered body, except for the thin dense outer layer with $50-100-\mu \mathrm{m}$ thickness that contacts the polyurethane mold during solidification. This channeled structure is different from foam structures ${ }^{1}$ where spherical pores are associated with almost fully dense struts and (narrow) windows. Unlike the flat ellipsoidal cross-sections ${ }^{14-17}$ in conventional aqueous freeze casting, these pore channels have nearly circular cross-sections. The diameters of channels increase for samples made with lower solids contents in the slurries, as is clearly seen in Figs. 3 and 4. Note that walls surrounding channels are almost fully dense. The surfaces of the walls facing channels are very smooth, like as-fired surfaces.

\section{(2) Camphene Dendrites in Very Dilute Suspensions}

To understand the mechanism of the formation of this structure, the solidification behavior of the camphene-based slurries was examined by optical microscopy. A dilute slurry with only 3 vol $\% \mathrm{Al}_{2} \mathrm{O}_{3}$ was prepared by the same warm ball-milling method. The concentration of $3 \mathrm{vol} \%$ was chosen so that the slurry would be translucent enough for optical observation with transmitted light. The slurry was dropped onto a pre-warmed slide glass having almost the same temperature as the slurry, covered by a pre-warmed cover glass, and allowed to freeze at room temperature. The microstructures were observed by optical microscopy. Figure 5 shows some typical solidified microstructures of the camphene-based dilute slurry. Dendritic growth of camphene is observed (Figs. 5(a) and (b)) and most of the observed area is covered with overgrown dendrites (Fig. 5(c)). SEM was also conducted for the solidified droplet after the camphene was removed by freeze-drying. The same warm slurry was dropped onto a pre-warmed slide glass. It was solidified at room temperature without a cover glass and then freeze-dried in an ambient atmosphere to sublime all the camp- 

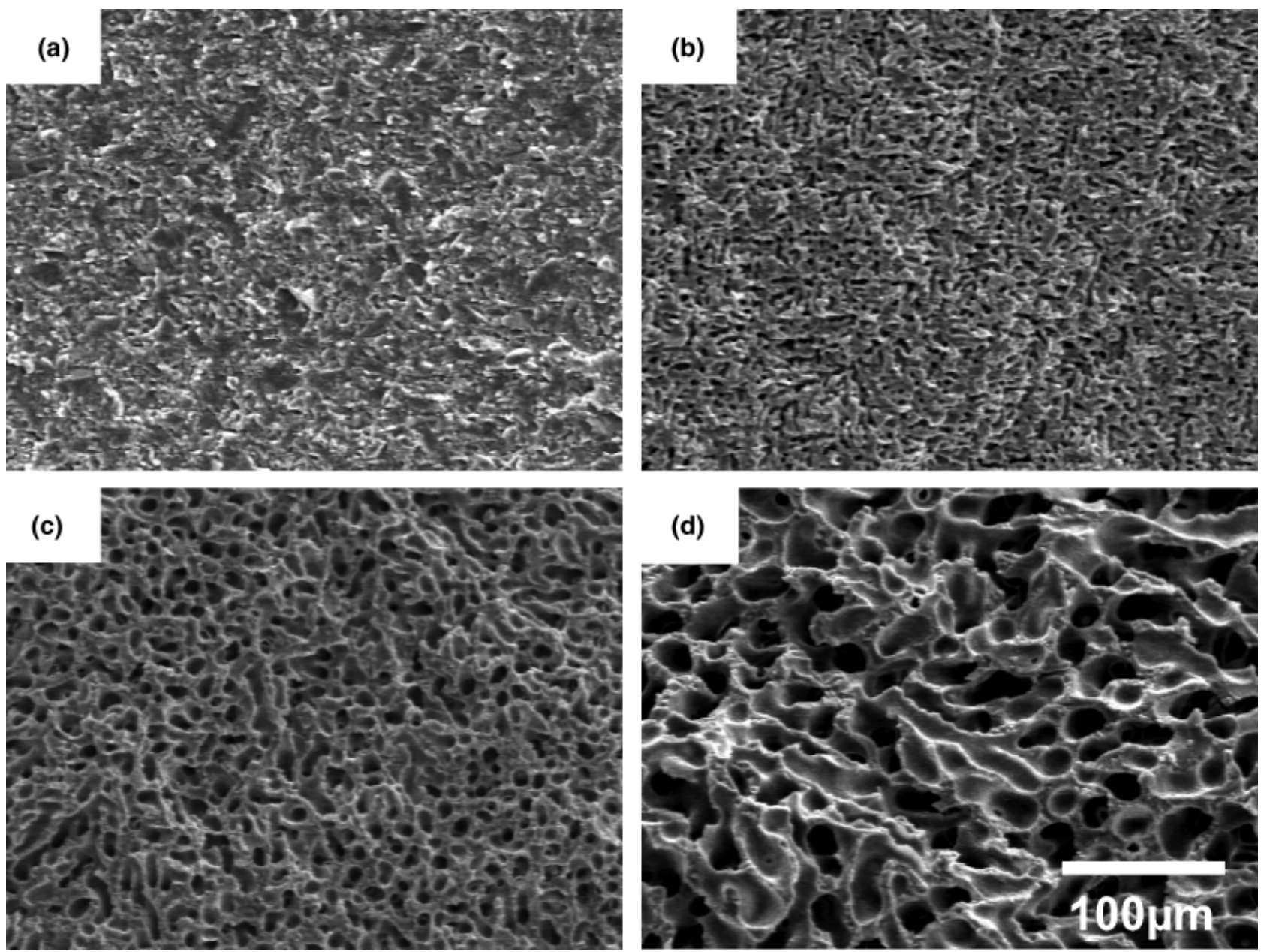

Fig. 3. Fracture surfaces of the sintered bodies from (a) 52.3, (b) 43.3, (c) 33.4 , and (d) 22.6 vol\% solid content slurries. Magnification in this figure is higher than that in Fig. 4.

hene from the solidified droplet. Figure 6 shows some typical microstructures of the $\mathrm{Al}_{2} \mathrm{O}_{3}$ remnants in the freeze-dried droplet on the slide glass. Interconnected ribs, which are obviously made of $\mathrm{Al}_{2} \mathrm{O}_{3}$ powder, are observed. These ribs replicate the interdendritic spaces in Fig. 5 (see just above the scale in Fig. 6(a)).

\section{(3) Unidirectional Solidification}

Since it seemed likely that the channels form as replicas of camphene dendrites, unidirectional solidification was tried to control the growth direction of the camphene dendrites. A special mold composed of an aluminum bottom plate and a silicone rubber cap on it (Fig. 7) was prepared to create a cylindrical cavity. The cavity size was $30 \mathrm{~mm}$ in diameter and $15 \mathrm{~mm}$ in height. Warm ball-milled $\mathrm{Al}_{2} \mathrm{O}_{3}$ slurry of $55^{\circ} \mathrm{C}$ with $33.4 \mathrm{vol} \%$ solid content was poured at room temperature into the prewarmed mold having almost the same temperature as the slurry. Just after casting, iced water was poured into the outer container to chill only the aluminum bottom plate so that the solidification of the camphene-based slurry would occur unidirectionally from the bottom towards the top in the mold. The solidification was completed in about $5 \mathrm{~min}$ in this case. The cast body was then freeze-dried in an ambient atmosphere and sintered.

Figure 8 shows typical microstructures in the unidirectionally solidified body after sintering. Channels replicating dendrites with growing direction parallel to the solidification direction are observed in vertical cross-sectional views (Figs. 8(a) and (b)). No dendrites were observed growing in the horizontal cross-sectional views (Figs. 8(c) and (d)). Instead, a hole connected with four short channels, whose directions are perpendicular to the holes (i.e., on the cross-section), is observed (Fig. 8(d)). Thus, a porous body with aligned channels is obtained by unidirectional freeze casting using camphene as a vehicle. The channeled pore structure exists throughout the sintered body, except for a thin dense outer layer with $200-\mu \mathrm{m}$ thickness on the side wall that touches the rubber mold during solidification and a very thin dense layer with less than $10-\mu \mathrm{m}$ thickness at the free top surface. The channel sizes become larger with distance from the bottom plate as is observed in aqueous directional freeze casting. ${ }^{17}$ Relative density and open and closed porosity of the unidirectionally solidified body are summarized in the Table I. Most pores in this sintered body are open pores. This means that the channels are almost fully connected with each other and open to the surface. Relatively small porosity differences are observed along the solidification direction (Table II) as measured for slices sectioned into four pieces with $2.5-\mathrm{mm}$ thickness from the sintered, unidirectionally solidified body.

\section{Discussion}

Camphene $\quad\left(\mathrm{C}_{10} \mathrm{H}_{16}, \quad\right.$ 2,2-dimethyl-3-methylene-bicyclo [2.2.1]heptane) is a cyclic hydrocarbon, as shown in Fig. 9, and a crystalline plastic solid at room temperature. Camphene is a terpenoid, a natural material, commonly used in fragrance compounds. Camphene has a melting temperature around 44 $48^{\circ} \mathrm{C}$ and liquid viscosity of $1.4 \mathrm{mPa} \cdot \mathrm{s}$ at $47^{\circ} \mathrm{C} .{ }^{28}$ The solidification volume change is $-3.1 \%{ }^{28}$ (shrinkage). The crystal structure of camphene at the melting point is body-centered cubic (bcc). ${ }^{29}$

The solidification behavior of camphene has been studied by several researchers. ${ }^{29-33}$ It is known that camphene forms dendrites when solidified under an appropriate temperature 

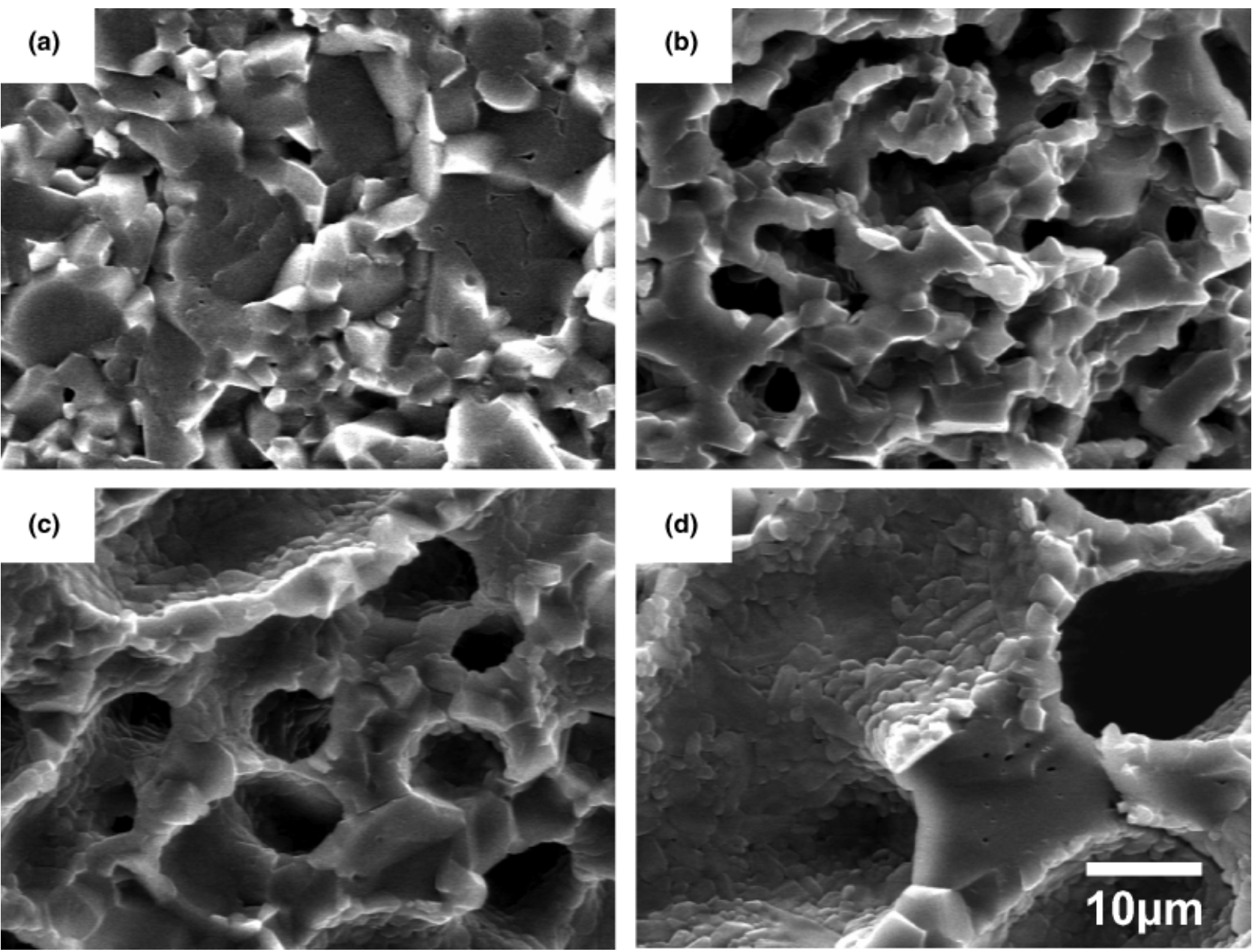

Fig. 4. Scanning electron micrograph of the freeze-dried droplet of $3 \mathrm{vol} \% \mathrm{Al}_{2} \mathrm{O}_{3}$ slurry. Interconnected ribs with unique structure are observed. These ribs seem to replicate the interdendritic spaces in Fig. 5 (see, e.g., just above the scale in (a)).

gradient ${ }^{30}$ or a solute gradient in an alloy system. ${ }^{31}$ Dendrite morphology and growth kinetics of highly purified camphene and as-received camphene ( $>95 \%$ purity) are well discussed in Rubinstein and Glicksman ${ }^{32}$ and Çadirli et al., ${ }^{33}$ respectively. Even in the nondirectional solidification in the present work where a polyurethane mold was used as a thermal insulator, temperature gradient in the slurry is inevitable. Moreover, since the liquid phase in the slurry is a multicomponent system, i.e., a mixture of molten commercial $( \pm)$-camphene and a liquid dispersant, a solute gradient is likely to occur in the liquid phase during solidification. Thus, it is reasonable that the dendrite formation of camphene occurs during freeze casting.

While solute redistribution at a solid-liquid interface during solidification has been extensively studied in metal alloys and saline solutions, ${ }^{34}$ little research had been conducted for the interaction between foreign particles in the liquid and a solidliquid interface during solidification until 1964. Uhlmann et al. ${ }^{35}$ studied this interaction using fine metal or ceramic powders that were dispersed in organic vehicles such as salol, thymol, and orthoterphenyl. They observed that particles are rejected by the solid-liquid interface and pushed along ahead of the advancing interface when the interface velocity is below a certain value. Although the interface they observed was a faceted planar interface, almost the same concept seems applicable to the interface of the dendrites. The only difference is that the particles are not pushed along ahead of the advancing macroscopic solidification front composed of tips of growing dendrites, but concentrated between dendrite arms or neighboring dendrites on the spot after being rejected by dendrite arms. The channeled structure observed throughout the body and almost the same porosity along the solidification direction (Table II) support this idea. The unique ribs, replicating well the interdendritic spaces (Fig. 6), also support the idea. Thus, it seems reasonable that most of the ceramic particles in the slurry were rejected by the growing dendrites and concentrated on the interdendritic spaces. Actually, interconnected pores or channels in porous bodies by conventional aqueous freeze casting are also regarded as replicas of entangled dendritic crystals of frozen ice. ${ }^{14-17,22}$

As seen from the discussions above, it is no wonder that channels replicating dendrites with growing directions parallel to the solidification direction are observed in the vertical crosssectional views (Figs. 8(a) and (b)). A hole and four short channels connected with it in the horizontal cross-sectional views (Fig. 8(d)) are considered to be a replica of a cross-section of primary dendrite arms that are connected with four short secondary arms on the plane.

Particle rejection in front of the growing dendrites increases the concentration of particles in the remaining liquid slurry. Since the walls surrounding the channels in the sintered body are dense, the concentration of the rejected particles in the remaining slurry in interdendritic spaces (which freezes later than the dendrites) was at least $50 \mathrm{vol} \%{ }^{23}$ It is possible that particle rejection continues until the remaining slurry is concentrated to near close packing. Higher powder packing in the ribs (Fig. 6(b)) of the dilute slurry supports this estimate.

One interesting observation is that the channeled structures are observed throughout the body. This means that dendrites in the camphene-based slurry are easy to grow and do not stop growing until the sample ends. Although incomplete growth of dendrites is observed in Figs. 5(a) and (b), it is noted that this model experiment is pseudo-two-dimensional solidification, which is different from three-dimensional solidification in the 


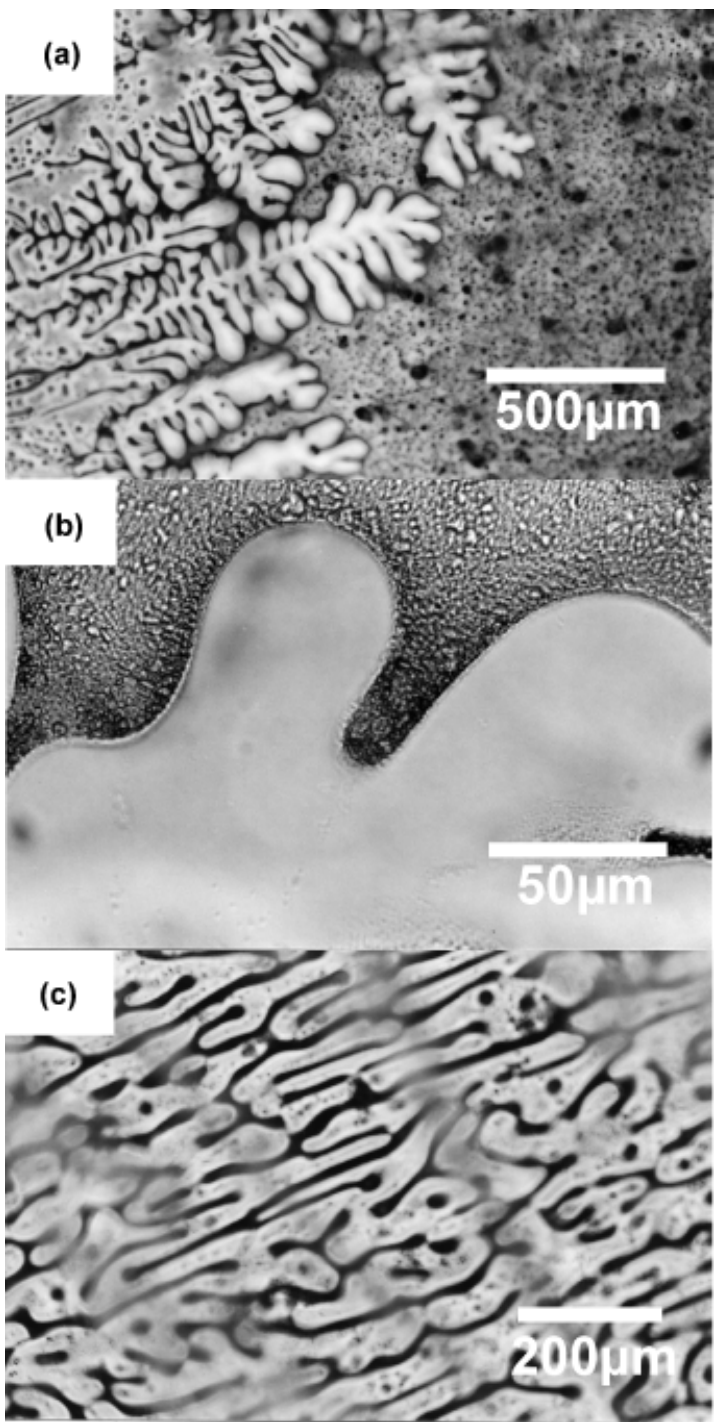

Fig. 5. Optical micrographs of camphene dendrites in the as-solidified $3 \mathrm{vol} \% \mathrm{Al}_{2} \mathrm{O}_{3}$ slurry. The area where no dendrites are seen (the right side in (a) and the upper side in (b)) is also solidified with nondendritic features. Magnified picture of (a) is shown as (b). Most of the observed area was covered with overgrown dendrites as shown in (c).

cast bodies. In Fig. 5(a), the left side was chilled so that camphene dendrites could grow two-dimensionally towards the right side. During the growth of dendrites, however, solidification of
Silicone Cap

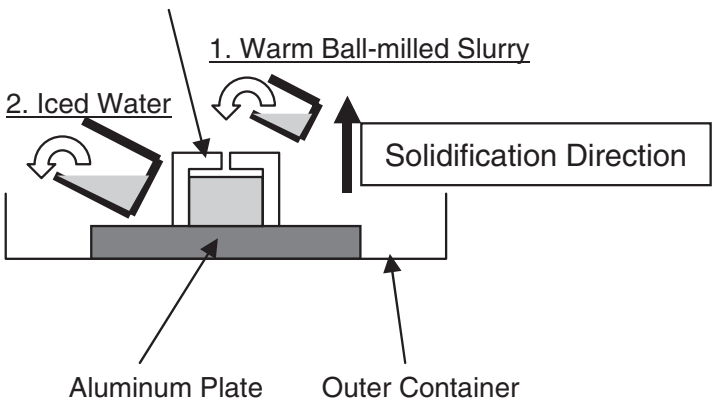

Fig. 7. Schematic illustration of the unidirectional solidification process. Only the aluminum bottom plate is chilled by iced water so that the slurry unidirectionally solidifies from the bottom.

the liquid from the bottom glass plate towards a top cover plate occurred at the same time to form nondendritic structure, which stopped the growth of dendrites from the left side. This is the reason why dendritic growth is incomplete in Fig. 5. It is noted again that a replica of such incomplete dendritic growth was not observed in the sintered bodies.

To describe solidification (freezing) behavior of materials, Jackson and Hunt $^{29}$ introduced a parameter $\alpha=\left(L / R T_{\mathrm{E}}\right) \xi$ where $L$ is the difference between the internal energy of the liquid and solid phase, $R$ is gas constant, $T_{\mathrm{E}}$ is the equilibrium temperature between the two phases, and $\xi$ is a factor that depends on the crystallography of the interface. The value of $\xi$ is between $1 / 2$ and 1 for the closest packed face of the crystal, and decreases for higher index planes. The factor $L / R T_{\mathrm{E}}=\Delta S_{\mathrm{f}} / R$ is the entropy of melting (dimensionless). Materials with $\alpha<1$, like most metals, are likely to grow dendritically into undercooled melts, whereas materials with larger $\alpha$ are bounded by large flat crystal faces during growth. ${ }^{29}$ The factor $L / R T_{\mathrm{E}}$ for camphene is $\sim 1.1,{ }^{36}$ whereas that of salol, which usually grow in a faceted manner, is $7 .{ }^{29}$ The factor $L / R T_{\mathrm{E}}$ of $\sim 1.1$ for camphene is even smaller than those for tin $(\sim 1.7)^{36}$ and water $(\sim 2.6),{ }^{36}$ both of which exhibit easy dendritic growth. The smaller $L / R T_{\mathrm{E}}$ for camphene may contribute to easy dendrite formation in this work, resulting in the channels observed throughout the body.

To summarize, the formation mechanism of the unique porous structure in the sintered body can be explained by the following steps: (1) formation of camphene dendrites during the slurry solidification, $(2)$ rejection of ceramic $\left(\mathrm{Al}_{2} \mathrm{O}_{3}\right)$ particles by growing dendrites, (3) concentration of the slurry until more than $50 \mathrm{vol} \%$ or even almost fully close packing on the interdendritic spaces, (4) completion of the solidification, (5) channel formation as replicas of entangled dendrites after camphene
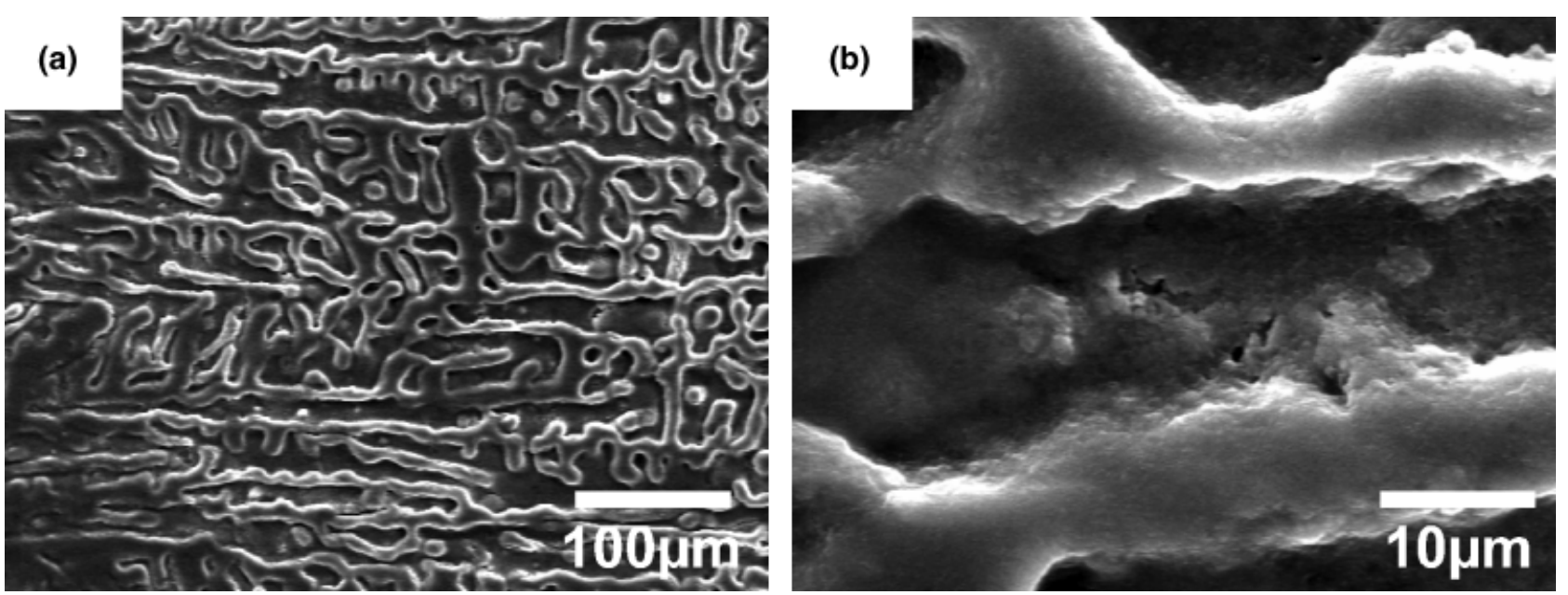

Fig. 6. Typical microstructures of the $\mathrm{Al}_{2} \mathrm{O}_{3}$ remnants in the freeze-dried droplet show interconnected ribs of the interdendritic spaces. The ribs are made of $\mathrm{Al}_{2} \mathrm{O}_{3}$ powder (a). Higher powder packing after freezing (b) is concentrated to our close packing. 

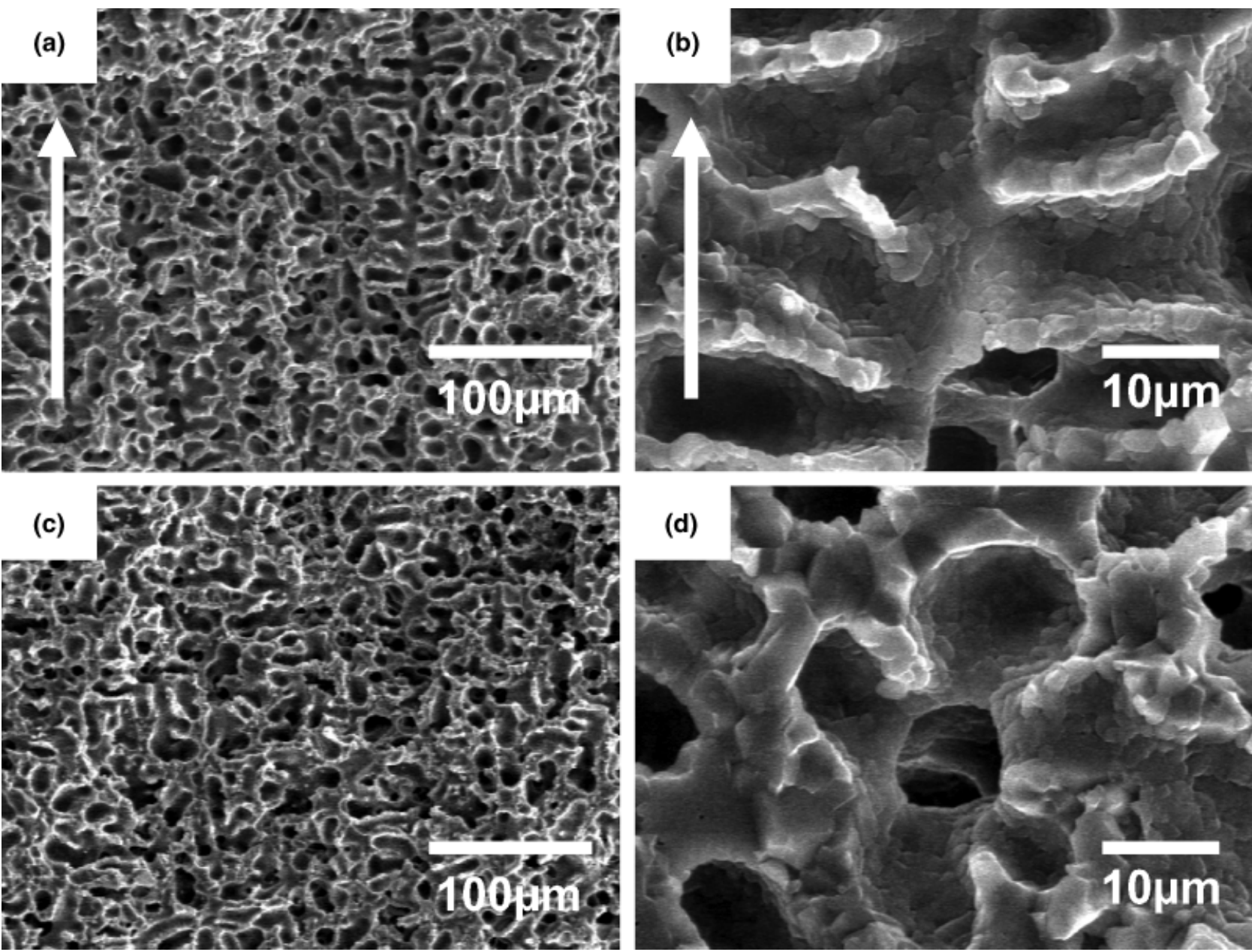

Fig. 8. Microstructures of (a), (b) vertical, and (c), (d) horizontal cross-sectional views in the sintered, unidirectionally solidified body. Arrows in the figure indicate the solidification direction. Solidification proceeded towards readers in (c) and (d). Cross-sections were made by fracture.

sublimation (freeze-drying), and (6) formation of almost fully dense walls on former interdendritic spaces by sintering.

\section{Summary}

Porous ceramic bodies with interconnected pore channels were fabricated by a freeze casting technique using camphene-based slurries with lower solids contents. The unique channels have nearly circular cross-sections, unlike flat ellipsoidal ones in conventional aqueous freeze casting. The channels are surrounded

Table I. Relative Density, Open and Closed Porosity of the Cylindrical Unidirectionally Solidified Body After Sintering

\begin{tabular}{lcc}
\hline Relative density (\% TD) & Open porosity (\%) & Closed porosity (\%) \\
\hline 57.8 & 41.0 & 1.2 \\
\hline
\end{tabular}

$\mathrm{TD}$, theoretical density.

Table II. Porosity Distribution Along Solidification Direction in the Sintered Unidirectionally Solidified Body

\begin{tabular}{lc}
\hline Position & Porosity (\%) \\
\hline Top & 39.9 \\
Upper middle & 42.5 \\
Lower middle & 43.5 \\
Bottom & 39.6 \\
\hline
\end{tabular}

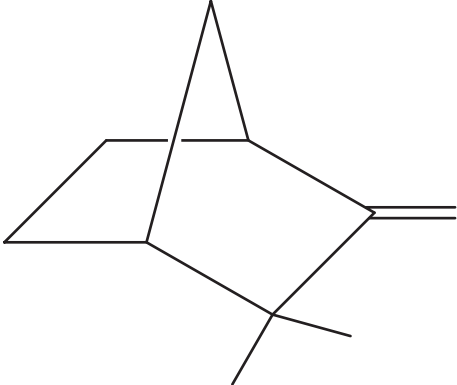

Fig. 9. Structural formula of camphene, $\mathrm{C}_{10} \mathrm{H}_{16}$.

by almost fully dense walls. Porosity and channel diameters increase with decreases in the solid content in the slurries. The formation mechanism of the porous structure in the sintered body can be explained by an analogy of the particle rejection model primarily developed for interaction between foreign particles and a faceted, planar solid-liquid interface.

\section{References}

${ }^{1}$ K. Ishizaki, S. Komarneni, and M. Nanko, Porous Materials-Process Technology and Applications; pp. 1-11. Kluwer Academic Publishers, Dordrecht, the Netherlands, 1998

${ }^{2}$ L. L. Hench, "Bioceramics," J. Am. Ceram. Soc., 81 [7] 1705-28 (1998).

${ }^{3}$ J. W. Cahn and J. E. Hilliard, "Free Energy of a Nonuniform System: III, Nucleation in a Two-Component Incompressible Fluid," J. Chem. Phys., 31 [3] 688-99 (1959)

${ }^{4}$ J. W. Cahn, "Spinodal Decomposition," Acta Met., 9 [9] 795-801 (1961). 
${ }^{5}$ M. Hillert, "A Solid-Solution Model for Inhomogeneous Systems," Acta Met., 9 [4] 525-34 (1961).

${ }^{6}$ H. P. Wood and M. E. Nordberg. "Method of Treating Borosilicate Glasses," U.S. Patent No. 2,215,039, 1940.

${ }^{7}$ R. J. Charles, "Phase Separation in Borosilicate Glasses," J. Am. Ceram. Soc., 47 [11] 559-63 (1964).

${ }^{8}$ K. Nakanishi and N. Soga, "Phase Separation in Gelling Silica-Organic Polymer Solution: Systems Containing Poly(Sodium Styrenesulfonate)," J. Am. Ceram. Soc., 74 [10] 2518-30 (1991).

${ }^{9}$ K. Nakanishi, "Pore Structure Control of Silica Gels Based on Phase Separation," J. Porous Mater., 4, 67-112 (1997).

${ }^{10}$ R. Takahashi, S. Sato, T. Sodesawa, K. Suzuki, M. Tafu, K. Nakanishi, and N. Soga, "Phase Separation in Sol-Gel Process of Alkoxide-Derived Silica-Zirconia in the Presence of Polyethylene Oxide," J. Am. Ceram. Soc., 84 [9] 1968-76 (2001).

${ }^{11}$ K. Nakanishi, R. Takahashi, T. Nagakane, K. Kitayama, N. Koheya, H. Shikata, and N. Soga, "Formation of Hierarchical Pore Structure in Silica Gel," J. Sol-Gel Sci. Technol., 17, 191-210 (2000).

${ }^{12}$ S.-H. Li, J. R. de Wijn, P. Layrolle, and K. de Groot, "Novel Method to Manufacture Porous Hydroxyapatite by Dual Mixing," J. Am. Ceram. Soc., 86 [1] 65-72 (2003).

${ }^{13}$ T. Yokota, "Fabrication of Ceramics with Highly Aligned Pores (in Jpn.)," Kemikaru Enginiyaringu (Chem. Eng.), 42 [11] 845-51 (1997).

${ }^{14}$ T. Fukasawa, M. Ando, T. Ohji, and S. Kanzaki, "Synthesis of Porous Ceramics with Complex Pore Structure by Freeze-Dry Processing," J. Am. Ceram. Soc., 84 [1] 230-2 (2001).

${ }^{15}$ T. Fukasawa, Z.-Y. Deng, M. Ando, T. Ohji, and S. Kanzaki, "Synthesis of Porous Silicon Nitride with Unidirectionally Aligned Channels Using Freeze-Drying Process," J. Am. Ceram. Soc., 85 [9] 2151-5 (2002).

${ }^{16} \mathrm{~T}$. Fukasawa, Z-Y Deng, M. Ando, T. Ohji, and Y. Goto, "Pore Structure of Porous Ceramics Synthesized from Water-Based Slurry by Freeze-Dry Process," J. Mater. Sci., 36, 2523-7 (2001).

${ }^{17}$ D. Koch, L. Andresen, T. Schmedders, and G. Grathwohl, "Evolution of Porosity by Freeze Casting and Sintering of Sol-Gel Derived Ceramics," J. SolGel Sci. Technol., 26, 149-52 (2003).

${ }^{18}$ K. A. Jackson, "Mechanism of Growth;" pp. 174-186 in Liquid Metals and Solidification. Edited by M. Moddin. ASM, Cleveland, OH, 1958.

${ }^{19}$ H. Ballman, "Unique New Forming Technique," Ceram. Age, 791, 36-8 (1957)

${ }^{20}$ B. E. Novich, C. A. Sundback, and R. W. Adams, "Quickset Injection Molding of High-Performance Ceramics;" pp. 157-64 in Ceramic Transactions, Vol. 26,
Forming Science and Technology for Ceramics, Edited by M. J. Cima. American Ceramic Society, Westerville, OH, 1992.

${ }^{21}$ R. W. Jones, "Near Net Shape Ceramics by Freeze Casting," Ind. Ceram., 20 [2] 117-21 (2000).

${ }^{22}$ S. W. Sofie and F. Dogan, "Freeze Casting of Aqueous Alumina Slurries with Glycerol,” J. Am. Ceram. Soc., 84 [7] 1459-64 (2001).

${ }^{23} \mathrm{~K}$. Araki and J. W. Halloran, "A New Freeze Casting Technique for Ceramics with Sublimable Vehicles,” J. Am. Ceram. Soc., 87 [10] 1859-63 (2004).

${ }^{24}$ E. R. Herrmann, "Molding Comminuted Nonplastic Inorganic Material," U.S. Patent No. 3,330,892, 1967.

${ }^{25}$ C. A. Sundback, B. E. Novich, A. E. Karas, and R. W. Adams, "Complex Ceramic and Metallic Shaped by Low Pressure Forming and Sublimative Drying," U.S. Patent No. 5,047,182, 1991.

${ }^{26}$ J. E. Jordan (ed.), Vapor Pressure of Organic Compounds. Interscientific Publishers, Inc., New York, 1954.

${ }^{27}$ K. Ishizaki, S. Komarneni, and M. Nanko, Porous Materials-Process Technology and Applications; pp. 202-4. Kluwer Academic Publishers, Dordrecht, the Netherlands, 1998

${ }^{28}$ T. E. Daubert and R. P. Danner, Physical and Thermodynamic Properties of Pure Chemicals: Data Compilation, Part 4. Taylor \& Francis Publishers, London, 1989.

${ }^{29}$ K. A. Jackson and J. D. Hunt, "Transparent Compounds That Freeze Like Metals," Acta Met., 13, 1212-5 (1965).

${ }^{30}$ S. C. Huang, "Dendritic Growth at Small Supercodings," PhD thesis, Materials Engineering, Rensselaer Polytechnic Institute, Troy, NY, 1979.

${ }^{31} \mathrm{M}$. Chopra, "Influence of Diffusion and Convective Transport on Dendritic Growth in Dilute Alloys," PhD thesis, Materials Engineering, Rensselaer Polytechnic Institute, Troy, NY, 1984.

${ }^{32}$ E. R. Rubinstein and M. E. Glicksman, "Dendritic Growth Kinetics and Structure II. Camphene," J. Cryst. Growth, 112, 97-110 (1991).

${ }^{33}$ E. Çadirli, N. Marasli, B. Bayender, and M. Gündüz, "Dependency of the Microstructure Parameters on the Solidification Parameters for Camphene," Mater. Res. Bull., 35, 985-95 (2000).

${ }^{34}$ J. P. Terwilliger and S. D. Dizio, "Salt Rejection Phenomena in the Freezing of Saline Solutions," Chem. Eng. Sci., 25, 1331-49 (1970).

${ }^{35}$ D. R. Uhlmann, B. Chalmers, and K. A. Jackson, "Interaction Between Particles and a Solid-Liquid Interface," J. Appl. Phys., 35, 2986-93 (1964).

${ }^{36}$ D. R. H. Jones, "Review-The Free Energies of Solid-Liquid Interfaces," J. Mater. Sci., 9, 1-17 (1974). 